\title{
Antecedents of Women Workforce Conflict and Turnover: The Role of Culture and Environment
}

\author{
Zarmina Khan \\ Karachi University Business School, University of Karachi, Pakistan \\ E-mail: z_khan_1991@hotmail.com \\ Dr. Danish Ahmed Siddiqui \\ Karachi University Business School, University of Karachi, Pakistan \\ E-mail: daanish79@hotmail.com
}

Received: April 3, 2020 Accepted: April 28, 2020 Published: May 1, 2020

doi: 10.5296/hrr.v4i1.16798 URL: https://doi.org/10.5296/hrr.v4i1.16798

\begin{abstract}
Resolving workforce conflict and turnover issues have being a great concern. Even a greater challenge is to know how this conflict takes place. Organizations working to overcome gender inequality find it even more difficult to cope up with this situation when conflict arises in the Women Workforce. This study aims to explore the reason for Women Workforce conflict and turnover, and particularly explore the role of culture and environment. We proposed a theoretical framework explaining this phenomenon. We hypothesized that various factors such as Psychological work factors, lack of Diversity, incivility, Discriminatory HR planning, no identity separation, and Gender inequality negatively affect both work both culture and environment. And this would ultimately lead to women workforce turnover and conflicts. We establish its empirical validity by conducting a survey using a close-ended questionnaire. Data was collected from 314 individuals and analyzed using confirmatory factor analysis and structured equation modeling. The results showed that Diversity, and Identity Separation have a positive whereas Gender Inequality, and Discriminatory HR Planning have a negative significant effect on the Work Environment. Moreover, the work environment in turn positively affects Women Workforce Turnover and Workforce Conflict. Psychosocial work Factors also positively affect work culture, which subsequently affects both and Women Workforce Turnover, and Conflict. Hence work environment, and culture both play an effective mediatory role in-between these factors and Women Workforce
\end{abstract}




\section{Macrothink}

Turnover, and Conflict. Findings imply that Culture and work environment should have been considered in a professional and well-directed manner.

Keywords: HR Policies, Incivility, Diversity, Women Turnover, Culture, and Work Environment Contents

\section{Introduction}

\subsection{Background of the Study}

The organizational environment is an important part of the work environment and has been focused on reducing aggressive behavior. People interact more with demographic groups (colleagues and acquaintances working outside the workplace) and need more collaboration between similar demographic groups. Also, many jobs can be found via social media, not the official application procedure. Similar demographic staff therefore, social networks tend to overlap. Reputation for bad behavior is easier to spread among people who share the population and those who violate group rules may be more effective in that group. Jobs provide employees with a variety of public goods and employee-friendly work, affecting all employees. The range of these items is plentiful and includes the complexity of playing good music at the workplace, beautiful outfits, language features and enjoying more time for friends and others behind the scenes. If population heterogeneity increases the priority equality, then diversity can reduce the overall satisfaction rate of a universal product mix. In general, small demographic differences can easily fit into the unique demographics of the demographic. These effects allow employees to become more homogeneous. Conversely, a lower category may reduce some public goods.

Chen, Wang and Tang (2016) describe workplace incivility as "low-intensity crime, a violation of mutual respect at work, with the intention of closing an object". However, to qualify for torture, you must hide the malicious intent of one or more parties involved. Over time, the level of distraction, dissatisfaction, creativity and cooperation decreases, and the level of psychological suffering increases and the level of organizational commitment and resignation increases. Previous studies have provided insight into the definition of discomfort, its impact and an understanding of other forms of workplace violence. Questions have been raised about hostile views of certain civilians and groups, such as gender and race. There are many similarities with violence, sexual harassment and racism.

Researchers say that participation is closely related to organizational responsibility and employee retention. In 2004, researchers at the company management said that by increasing $10 \%$ of employee engagement, this would reduce employee energy levels by $6 \%$ and increase their performance level. $2 \%$. Individual organizations, essential to bridge the gap between workplace research and employee relationships, are essential to meeting with company leaders. From the standpoint of human resources, loyal employees will continue and continue to work (Choi, 2018).

Workplace or organizations offering jobs are often referred to as inhospitable for the placement of females. This phenomenon is a common practice among organizations and it exists due to certain perspectives of gender inequities that have been developed, propagated and prevailed for the last century in the workplace (Burgess \& Borgida, 1999). These discriminations arose primarily due to wrong concepts and stereotypes that restrict the 


\section{MInstitute Macrothink $_{\text {Int }}$}

women to confine themselves to certain tasks and activities of life; managing the household and raising the children. These negative concepts have drastically imparted negative impacts on the professional development of women in certain aspects of life. These concepts have drastically disrupted the women's rights that allow women to pursue a career or job of their talents depending upon their intellect and talent (Mobley, 1982). At the organizational level, there is a great extent of trends in sexism that allow males to secure more benefits and opportunities than that of women. It has been noticed that due to the lack of Diversity Management, certain companies and organizations are failing to maintain the inclusiveness of both males and females in the job activities and maintain a balance where the phenomenon of gender discrimination is degraded. When the organizations fail to establish terms and conditions based on the theories of diversity management and inclusiveness in their Human Resource management departments, they develop trends of sexism among the employees as a consequence of which, women's rights at the workplace are greatly affected and disrupted (Hom \& Griffeth, 1995).

Besides this, it has been reported that women are subjected to sexist comments at their job place. It has been evaluated that this problem; subjective stigma, low pay rate, low rate of employment opportunities and less chance of getting promoted have significantly increased the rate of women's physical stress, physical health and psychological health and consequently, have promoted less satisfaction at job place that resulted in low progress and job performance of women in an organization (Burgess \& Borgida, 1999).

\subsection{Problem Statement}

The discrimination factor between male and female workforce has been increasing and create certain issues and problems in Pakistan. Due to ineffective equality, problems such as women's turnover are increasing. Apart from inequality, HR Policies, incivility and ineffective diversity are some of the elements that push the workforce towards more jeopardy. Most of the organizations of the world are now facing the problem of inequity and inequality. Therefore, a positive attitude should have been considered for their competitiveness in bringing effective change in society. Most of the organizations across the globe are maintaining values for their development and efficiency.

\subsection{Gap Analysis}

Jabeen, Friesen and Ghoudi (2018) provide evidence that emotionally expensive work affects women more than men. Santhanam et al. (2015) examined gender impacts on stressful processes and concluded that men and women can meet traditional social criteria. The studies that have been mentioned earlier were conducted in the Western markets and emphasized more on the employees' satisfaction through effective HR policies and others. However, this study is somewhat different in which it focuses mainly on Pakistan, in which the intensity of women's empowerment and diversity problem is high. Moreover, this research has covered more variables such as HR policies, incivility and discrimination that put more emphasis on the same connection for providing everything accordingly. Particularly this research additionally focused on cultural and environmental aspects that were not covered before. Hence, it is a novel attempt to find the effect of multiple factors on women's workforce in the context of Pakistan combining them in a single structural model. 


\section{Macrothink}

\subsection{Research Objectives}

The first objective of this research is to examine the impact of HR policies on the diversity of the women turnover. Based on the same aspect, the HR policies in different Pakistani companies have been examined, and its impact has been visualized based on the turnover factor of the women. The second objective is also connected with the first one, in which more detailed information about civility and process of diversity has been examined, and its impact has been visualized on the turnover of the women in particular. Last, but not the least, the cultural and environmental factor has also been analyzed on the turnover of the women.

\subsection{Research Question}

1) How psychological workforce connected with the culture of an organization?

2) How collectivist culture of the organization impacts the diversity of the workforce for bringing new ideas and innovation?

3) How collectivist culture of the organization's impacts on the discrimination of HR planning?

4) How collectivist culture impacts on gender inequality?

5) How psychological workforce connected with the work environment of an organization?

6) How collectivist culture of the organization impacts the work environment for bringing new ideas and innovation?

7) How Discriminatory policies of the organization's impacts on their work environment?

8) How collectivist culture impacts on workforce turnover?

9) How collectivist culture impacts on the level of conflicts in an organization?

10) How discriminatory work environment impacts the women's turnover in organizations?

\subsection{Significance}

This research directly impacts on two different aspects. Firstly, women's empowerment and turnover have not been analyzed critically with the perspective of Pakistan. It means that different industries in Pakistan will get a complete idea about the importance and implication of equity in the market, and how equity could bring a high level of competitiveness for them. The effect would be tangible, as it helps the individuals to retain their employees for a long period that further leads to certain economic benefits in particular. It impacts positively on the organizational sector of Pakistan and impacts it accordingly.

Secondly, this research would be effective for future researchers as well to examine a similar notion in the future. Future researchers will get an idea about the importance of equity, and how the factor of equity would be ideal for their efficiency and betterment, especially in the long run.

\section{Gender Discriminations at Organizations}

Following are the possible cases and examples of gender discrimination at the workplace that might violate women rights and disrupt the professional development of women due to gender-based biases:

\subsection{Gender Wage Gap}

This is one of the most obvious and most observed examples of gender discrimination at the 
organizational level. It has been a common practice at certain organizations and companies that women are generally paid less than men. These gender biases have significantly propagated a lack of self-confidence and disappointment in women at work. This is certainly problematic because employees are not evaluated on the base of their talent and performance but based on what gender they belong to this problem has significantly led to decreasing trends in productivity among women employees at the workplace (Livanos, Yalkin, \& Nuñez, 2009).

The term Gender Wage gap is referred to as the potential difference among the wages of women and men at a particular place at a particular time. This phenomenon is of common observation in today's world (Angelov, 2016).

It might be observed in different countries and it has been prevailing in the world for a very long. The potential reason for this wage gap is primarily because of the gender discrimination that has been prevalent in the workplace and different organizations. The victims and assailants of the gender wage gap are more specifically women than that of men (Rubery \& Grimshaw, 2015). It is a phenomenon of common observation that women are generally paid fewer wages as compared to that of the men. There are two discrete types of wage gaps; the adjusted wage gaps and the non-adjusted wage gaps. The former one typically considers the number of hours that are designated for work, education, occupation types and the experience of work. For instance, a person who takes an off such as for maternity leave (a woman) is less opportune to earn as much as that if the person who does not take an off (a man). The non-adjusted female per annum salary is recorded to be $78 \%$ of the male's salary in the United States while it is $98 \%$ for the adjusted salary.

The current trends in the gender wage gap show a very low eradication rate and there is a serious need if incorporation if policies and norms that might eventually reduce the trend if gender wage gaps in different countries of the world (Connell, 2012). This paper will explore the features of this phenomenon and the possible reasons \& theories that are responsible for the prevalence of this issue in the workplace. As per Currie, Gormley, Roche \& Teague (2017), HR Policy, Decision-Making and Formulation clarify the differences between HR deployment, HR-related basic leadership and HR empowerment, and the relationships between them. Gender imbalances are a form of institutional separation.

\subsection{Questions Asked at the Time of Interview}

When it comes to interviewing, we note that women face gender-based or stereotyped questions by the interviewers. It is a common observation that women and men are questioned differently by employers at the time of the interview. Asking women about their family, children, and management of household and job might discriminate them from men. These questions should not have any place in the interviews because the placement of a person on a vacancy should be based upon the experience and skills of an individual.

\subsection{Fewer Responsibilities in the Workforce}

It has been noticed that women are considered fragile enough to handle a certain situation and carry things as men do at work (Nyberg, 2018). This is another mode of gender discrimination that is observed in different organizations and companies. This factor might contribute to the development of a lack of confidence amongst women at different 
organizations because they are restricted to work at the workplace because of their gender.

\subsection{Pregnancy}

It is a common practice at different organizations that pregnant women are victimized of gender biases and discrimination (William et al., 2018). A pregnant woman is highly discouraged to work at certain organizations because the HR departments and authorities assume that being pregnant makes women less competitive for a job and daily tasks as compared to that of men. However, certain federal and state laws largely discourage the practice of gender discrimination based on pregnancy at the workplace.

\subsection{Gender Biased Comments and Conversations at the Workplace}

It has been observed that women face a significant amount of unconscious or deliberate comments based on gender biases at their workplace (Altonji \& Bla, 1999). This is another type of stereotypic way in which women are victimized of gender biases at the workplace. Moreover, it is observed that the authorities address women and men is significantly different ways that might propagate the chance of gender discrimination at the workplace.

\subsection{Glass Ceiling}

It is a metaphor used in the professional terms to indicate a phenomenon where an unofficial hindrance to the progressive development in the profession is made by stereotypes more specifically for the women. A false concept of the glass ceiling has been made by different organizations to inhibit women from developing professionally at the workplace. It is another common example of gender discrimination at the workplace that women are subjected to. This phenomenon is also observed to create psychological and mental discouragement for the women and violates their basic right of working and pursuing a position of their choice based on their personal and professional skills \& talents (Livanos, Yalkin \& Nuñez, 2009).

\subsection{Radical Feminism}

Radical feminism has been a part of our society for decades, this type of orthodox thinking restricts the women to household and one step back as compared to the men. This phenomenon is still a part of certain societies and cultures such as the Asian cultures where women are considered inferior to men in the context of every aspect of life such as household decisions, work, and other matters. This typical phenomenon has organizations to impart gender discrimination at the time of employment, promotion, and perks for the employees because they always prefer men over women due to this outdated view of women workforce.

\subsection{Sexual Harassment}

Last but not the least factor contributing to gender discrimination at the workplace is the phenomenon of sexual harassment at the workplace that is a common practice among companies and organizations. It is one of the most important issues that need serious concerns at the workplace (Williams et al., 2018). Women are largely targeted by this phenomenon at their job place. It is reported that sexual harassment has significantly contributed to the diminished progressive development of women. Sexual harassment has significantly increased the ratios of psychological and mental stress in women at the workplace and has significantly refrained women to pursue the job and position of their interest by stepping them back from professional development. This factor has also contributed to the dominance of males at the workplace on females (Nyberg, 2018). 


\section{Theoretical Framework}

\subsection{Women Workforce Turnover}

Workforce turnover is a type of turnover, in which the turnover increases for the women at a higher intensity as compared to men. Researchers have shown adverse effects on sexual harassment and employee harassment on women workforce turnover. Low-intensity behaviors represent intangible, inactive and indirect consequences and stronger or more intense behaviors that show both proactive and direct consequences (Ayoko, 2016)

\subsection{Workforce Conflicts}

According to Pitafi, Liu \& Cai (2018) the explanations for workplace conflicts are personal, psychological, or authoritative factors that can cause workplace conflicts. Authoritative risk factors are insufficient assets, spells, job uncertainty, changes, poor physical condition, stress, and overtime Currie, \& Teague (2016), and preventive variables are social help for the career success of partners and bosses and vacancies. These elements are identified by a prestigious cultural and hierarchical atmosphere that describes the quality of the association. The former authoritative atmosphere gradually increased instead of a layered atmosphere with two structures and faster adjustments. According to Pitafi, Liu and Cai (2018) and Currie \& Teague (2016), personal and organizational factors that help reduce workplace conflicts. Researchers have previously hypothesized that uncivilized behavior can cause organizational negativity, eventually leading to major organizational conflict.

\subsection{Psychological Work Factors}

The psychological atmosphere of work is concerned not only with the structure and status of the network, the segmentation but also with the monetary and social aspects. It is recognized that money development, career advancement and efficiency, and social stability depend on the methods that are created, as well as the living and working conditions, on the prosperity and prosperity of employees and their families. Jnaneswar (2016) and Jabeen, Friesen \& Ghoudi (2018) identified that psychological factors are effective to bring new soul to the employees through which they can buy more effectiveness in the long run. However, Lapointe \& Vandenberghe (2017), negated the same idea as according to the psychological work factors are not efficient to maintain the workability accordingly.

Williams et al., (2018) researched to find the impact of psychosocial factors on the development of the conflicts at the workplace regarding more specifically in the case of women. The research was conducted through survey data that was collected by two employees. These two employees were studied in their workplace and results were generated correspondingly. It was found that there are several psychological factors that impact profound impacts on women at work as they undergo several psychological issues at a time.

Browne et al., (2018) conducted a systematic review of the impact of psychosocial factors to determine workplace disorders and intentions of employee turnover. For this review, papers were identified and scrutinized from some of the most reliable resources; PsycINFO, Web of Sciences database and PubMed. Forty-six papers suggested that psychosocial factors play a profound role in the determination of jib satisfaction, turnover number and other such disruption at the workplace faced by an organization.

Another research suggests that the psychological atmosphere of work is concerned not only 
with the structure and status of the network, the segmentation but also with the monetary and social aspects (Williams et al., 2018). This study correlates positively with the findings of Nyberg (2015) who researched by the data collected by the SLOSH (Swedish Longitudinal Occupational Survey of Health) where samples were collected of both male and female employees and it was found that money development, career advancement and efficiency, and social stability depend on the methods that are created, as well as the living and working conditions, on the prosperity and prosperity of employees and their families (Nyberg, 2015).

Studies have shown that there are several psychosocial and psychological factors (such as well-being and interface between work and personal life of an individual) that impart a great impact on the overall work. Mukarram (2012) found that it is the family-oriented psychological stress that gives an incline to the conflicts related to the female workforce in Pakistan. It has been claimed that psychological parameters are most important when it comes to workplace conflicts (Greenhaus \& Beutell, 1985). Moreover, Nyberg (2015) has found that female managers have been reported at a higher chance to face emotional demands, work \& personal life conflicts, low influence and high quantitative demands than male workers. In this way following hypotheses might be generated to test the impact of psychological factors on the workforce of female at workplace/ organizations of Pakistan:

H1. Psychological work factors are positively associated with the culture of an organization.

H2. Psychological work factors have a positive relationship with the work environment

\subsection{Diversity}

Diversity in the work environment is an association that uses the workforce intentionally, including people of different sex, religion, race, age, ethnicity, gender, orientation, training, and personalities. The versatility in the work environment offers many benefits, both internally and externally. In any case, this does not mean that you will be versatile in the workplace without new problems. Chen, Wang \& Tang (2016) and Choi (2018) put an assessment of workplace diversity in the health care system that helps HR and HR managers deal with stress and job satisfaction issues. A total sample of 150 individuals was selected to conduct the research in order to determine the impact of several factors on turnover rate of women in an organization. It was found that several psychosocial and other such impacts affect Workplace disruptions.

Several paradigms and theories have been identified to be used and implied in different perspectives of lack of diversity management and the subsequent gender discrimination at work (Cumming et al., 2015).

Following hypotheses are generated to test the inter-relationship of the diversity with culture and environment as stated in the prior literature:

H3. Diversity among the employees has a positive significant impact on the culture

H4. Diversity among the employees has a positive significant impact on the work environment

\subsection{Incivility}

Incivility is a term that promotes social behavior in the classroom or is rude, indifferent, cruelty or hooliganism to older people through open and destructive behavior. The term "instability" was derived from Latin incivilis meaning "non-resident." Low levels of non-civil 
behavior include many specific behaviors, such as sexual harassment, depression and micro-workplace behavior. Low-intensity behaviors represent intangible, inactive and indirect consequences and stronger or more intense behaviors that show both proactive and direct consequences

Pearson et al., (2000) found in his research by the survey of a questionnaire in a sample of 350 employees that the low levels of non-civil behavior include many specific behaviors, such as sexual harassment, depression and micro-workplace behavior. Low-intensity behaviors represent intangible, inactive and indirect consequences and stronger or more intense behaviors that show both proactive and direct consequences. Choi (2018) claimed that when an individual is in a state of stress, they feel intense anger revenge in fact; the passivity is often not obvious. Individual misconduct greatly affects the process and performance of the team. Part of the uncivilized spiral theory is a model of simple, disrespectful behavior in which an individual does not understand his situation and cannot change his behavior. Rude behavior of employees indicates that negative interactions have begun to increase (Yu, 2019).

One of the most negative outcomes of incivility is that it is contagious, that in a very short time uncivilized behavior becomes part of the culture and spreads as norms that produce long-term adverse effects and have a significant effect on general productivity (Anderson \& Pearson. 1999). Workplace incivility does not only affect those engaged but also on individuals around this contagious disease as they can also become carriers of it. Despite tackling several damaging implications of work incivility, it is still seen as a principal factor in every industry. It has been found to effect

H5. Workplace incivility has a significant negative impact on the culture

H6. Workplace incivility has a significant negative impact on the work environment

\subsection{Discriminatory HR Planning}

Instead, separation and sanctions of human resource-related options may come from the unilateral response by an authoritative leader. This is an individual separation. Upchurch and Grassman (2016) provides evidence for the highest-ranking CEOs to individually oppressed women when approving basic human resources-related leadership and human resources strategies In HRM, HR professionals and department managers can select candidates that match customer satisfaction and lower operating costs. Also, workplace injustice is somewhat similar to the definition of interaction, determined by the quality of personal interaction individuals receive during the workplace process.

The discriminatory policies of the Human Resource department might lead to the development of uncivil culture and disruptive environment which in turn might impart an effect on the female workforce turnover and might lead to the development of conflicts related to female workers at the workplace. Following hypotheses are generated based on this prior knowledge:

H7. Discriminatory HR planning has a significant negative impact on the culture

H8. Discriminatory HR planning has a significant negative impact on the work environment

\subsection{Identity Separation}

The positive and negative personal behavior of one employee can affect others. To increase investment in an organization, managers need to identify the causes and consequences of 
employee engagement, including finding a job. Institutional oppression of women occurs in a variety of human resource strategies for registering and identifying individuals through assignments, preparations, salaries, executive evaluations, promotions and departures. For example, if a woman is not participating in a particular education program or type of activity and should take this certification or past professional education into consideration, the woman is not sacrificed intentionally but is systematically adopted.

It has been found that identity separation has direct effects on the disputes that arise in terms of gender biases and discrimination (Pearson et al., 2000). That is how the following hypotheses have been generated to test the correlation of identity separation with culture and environment and hence finding the impacts on Female workforce turnover and conflicts.

H9. Identity separation has a positive relation with culture

H10. Identity separation has positive relation on the work environment

\subsection{Gender Inequality}

As per Avgar (2017) and Einarsen, Skogstad, Rørvik, Lande\& Nielsen (2018), in gender inequality, procedures, and practices, the association's sexual orientation imbalance is a complex miracle. For women, the most disruptive sexual orientation mismatches may be approved in human resource (HR) exercises. As per the opinion of Ayoko (2016), gender inequality theory explains environmental and social factors. Personal experience provokes aggressive behavior. All the factors that were actually discussed, they did not clearly describe the organizational atmosphere, which reflects the organizational factors that influence the state of events. However, recent research by Pitafi, Liu \& Cai (2018) has explored the role of climate in understanding and responding to workplace aggression and violence. The following research shows that climate affects violence and language invasion in an organization.

As per Avgar (2017) and Einarsen, Skogstad, Rørvik, Lande \& Nielsen (2018), in gender inequality, procedures, and practices, the association's sexual orientation imbalance is a complex miracle. For women, the most disruptive sexual orientation mismatches may be approved in human resource (HR) exercises. This is evidence-based on human resource exercises (i.e. preparations, basic leadership and their institutions) affecting women's enlistment, preparation, pay and promotion. We propose a gender-oriented isolation model in HR, which emphasizes the concept of proportionality of gender imbalances within associations. We recommend that gender-related segregation in the establishment of basic human resources-related leadership and human resource drills stems from a wider authority structure, gender imbalances in procedures and practices.

Certain theorists have given rise to a discourse of how stereotypes regarding female commitment to work have negatively disgraced the employment of females and restricted them in the persuasion of their professional development and career (Anker, 1997). That is how gender discrimination might impart impact the work environment and culture. The following hypotheses have been generated to find the impact of these factors upon the future and environment of an organization that will in turn find the relation of workforce conflicts and women turnover.

H11. Gender inequality has a significant negative impact on the work environment 


\section{Macrothink}

H12. Gender inequality has a significant negative impact on culture

\subsection{Collectivist Culture}

Collectivism is defined as the theory or concept of cohesiveness of members or individuals of an organization that leads to the prioritization of grouping and making classes instead of working individually upon something (Cialdini \& Trost 1998). As per Gifford, Gould, Latreille \& Urwin (2016) and Avgar (2017), the Collectivist Culture defines an integrated vision of the organization's policies, procedures and practices among its members. Such peritoneum varies significantly with interpretation, but both play an important role in tissue research.

It has been found that collectivist culture improves the upbringing of a team of employees working in an organization. The Collectivism Theory promotes a culture where each individual has equal opportunity to avail the chances of success, share ideas and get promoted (Anker, 1997). This culture propagates the trend of giving chances to everyone irrespective of the fact to which race they belong, what gender they have, what age group the secure and what ethnicity they hold, it gives strength to individuals from all domains of life. In this context, the following hypotheses were generated to find the relation between collectivist culture and women workforce turnover and women workforce conflicts.

H13. Collectivist culture has a significant positive effect on women workforce turnover

H14. Collectivist culture has a significant positive effect on Workforce conflicts

\subsection{Work Environment}

Yu (2019) contended that people who are characterized by a regular pattern of ups and downs can develop stress in the work environment due to a lack of understanding of their situational and behavioral change skills. Individuals experience a tantrum and respond positively to their goals. This further increases the impact of persistent uncivilized acts on harm. In each episode, the criminals increase their attacks significantly and increasingly aggressively towards the target.

Currie and Teague (2016) revealed that despite changing connections, the generalization of sexual orientation continues to thwart women's ability to overwhelm men. Ladies struggle with weakness, enthusiasm, deliciousness and initiative. Also, women are considered ordinary workers because they recognize that women are less loyal to their profession and are increasingly family-oriented. It is customary to sign in a manly place, reduce the chance of opening a business, and do not favor women because it does not properly get a male partner and does not shock anyone.

A healthy working environment is mandatory to bring the optimal working and consequences from an organization. It has been found that better working environments help the employees share their ideas in a better way, interact efficiently and learn from each other by maintaining the calibers or norms \& respect among each other (Pearson et al., 2000). Depending upon these assessments of a healthy environment, the following hypotheses have been generated to find the relationship among female workforce turnover, workplace conflicts and a better working environment for the employees of an organization.

H15. The better work environment has a significant negative impact on women workforce turnover 


\section{Macrothink}

Human Resource Research

ISSN 1948-5441

2020, Vol. 4, No. 1

H16. The better work environment has a significant negative impact on Workforce conflicts

\section{Methodology}

\subsection{Sampling}

The total sample size which has been covered in this entire study is 314 whose data has been found through online sampling and analysis.

\subsection{Questionnaire Design}

The research method provision should be effective and well-directed otherwise things might not go in the right direction. The research method is divided into two main types which are quantitative and qualitative. The quantitative research method is a method in which quantification numbers have been examined and explored accordingly. On the other hand, the qualitative research method is more towards the analysis through previous factors in particular. This particular research is based entirely on the quantification; therefore the research method is quantitative in particular. This outcome will be helpful for the researcher to examine the impact of women turnover in the Pakistani environment through different factors and elements. After the research method, the next valuable factor that examined in the same output is the data collection method. The data collection method has been divided into two main factors such as primary method and secondary data collection method. The primary data collection method is a method in which data is collected via a questionnaire, while the secondary data collection method is more towards the second factor and presented and covered data before. A close-ended questionnaire has been used which has been distributed to the individuals through different online mediums. The scale that has been used in each of the variables is Likert Scaling. The questionnaire has been adapted from different sources and the scale is Likert Scaling in which 5 options, 4 options and 7 options are given. The following table explains the questions developed for each variable along with the references, scaring and several questions per variable of the questionnaire developed.

\begin{tabular}{|c|c|c|c|c|}
\hline S. No & Variables & Source & Scale & $\begin{array}{l}\text { No. Of } \\
\text { Questions }\end{array}$ \\
\hline 1 & Work environment & Warr, P. (1990). & $\begin{array}{l}\text { Five-point Likert scale (from All of the time to } \\
\text { Never) }\end{array}$ & 12 \\
\hline 2 & Culture & $\begin{array}{l}\text { Hurst et. al. } \\
(2016)\end{array}$ & $\begin{array}{l}\text { Five-point Likert scale (from strongly disagree to } \\
\text { strongly agree) }\end{array}$ & 9 \\
\hline 3 & Workplace incivility & $\begin{array}{l}\text { Cortina et. al. } \\
(2001)\end{array}$ & $\begin{array}{l}\text { Three points Likert scale from (Never to More } \\
\text { than once or twice) }\end{array}$ & 7 \\
\hline 4 & Workplace conflicts & $\begin{array}{l}\text { Kinsten et. al. } \\
(2007)\end{array}$ & Four-point Likert scale (from Always to Never) & 5 \\
\hline 5 & Diversity & $\begin{array}{l}\text { Hurst et. al. } \\
\text { (2016). }\end{array}$ & $\begin{array}{l}\text { Four-points Likert scaling (from To a Great } \\
\text { Extent to Not at All) }\end{array}$ & 3 \\
\hline 6 & Gender inequality & $\begin{array}{l}\text { JL, L. F. Q. R. S. } \\
\text { (1971). }\end{array}$ & 7 and 4 points Likert scale & 3 \\
\hline 7 & $\begin{array}{l}\text { Human Resource } \\
\text { Planning (HRP) }\end{array}$ & $\begin{array}{l}\text { Kinsten et. al. } \\
(2007)\end{array}$ & $\begin{array}{l}\text { Seven-point Likert scale (from Strongly disagree } \\
\text { to Strongly agree) }\end{array}$ & 4 \\
\hline
\end{tabular}


8

Women Workforce Mayende \&

turnover Musenze (2018)

Psychosocial work Nyberg et. al.

9

factors

(2015).

Hippel et. al.

(2011).

\section{Analysis and Discussion}

\subsection{Preliminary Analysis}

\subsubsection{Demographics Analysis}

The first question that has been asked in the same connection was about the gender that has been included in the data collection purpose. The chart showing the gender distribution in the data collection purpose

\section{Gender}

\begin{tabular}{lll}
\hline & Frequency & Percent \\
\hline Male & 10 & 3.2 \\
Female & 304 & 96.8 \\
Total & 314 & 100 \\
\hline
\end{tabular}

Among a total of 314 respondents, around $97 \%$ were female while the remaining $3 \%$ were the male candidates. The main reason for having a high proportion of women in the data collection was the aim of the research that tilts more towards women. The next question is about the city from which the respondents belong

\section{City}

\begin{tabular}{lll}
\hline & Frequency & Percent \\
\hline Others & 16 & 5.1 \\
Islamabad & 2 & 0.6 \\
Lahore & 6 & 1.9 \\
Karachi & 290 & 92.4 \\
Total & 314 & 100 \\
\hline
\end{tabular}

290 out of 314 respondents who proportionate to $92.4 \%$ of the total respondents belong to Karachi, while others were 5.1\%. Having qualified respondents is essential for research, and the third question which has been asked from the respondents was about the degree they hold, and the answer is as follows

\section{Degree}

\begin{tabular}{lll}
\hline & Frequency & Percent \\
\hline Matriculation & 4 & 1.3 \\
\hline
\end{tabular}


High School

Bachelors

Masters

PHD

Technical

Total

\section{0}

87

169

21

13

314
6.4

27.7

53.8

6.7

4.1

100

Based on the above-mentioned table, it is found that most of the individuals were relating to the Masters Level, as $54 \%$ of the respondents were Masters, while $27 \%$ of the respondents were Bachelors. $6.7 \%$ and $6.4 \%$ of the respondents were connected with Ph.D. and High School degrees respectively. The age factor is also mandatory for a researcher to analyze, and the same is applicable in this research as well. The table shows the age of the respondents is as follows

\begin{tabular}{lll} 
Age & & \\
\hline & Frequency & Percent \\
\hline Less Than 20 & 10 & 3.2 \\
$20-25$ & 93 & 29.6 \\
$25-30$ & 131 & 41.7 \\
$30-35$ & 54 & 17.2 \\
$35-40$ & 16 & 5.1 \\
$40+$ & 10 & 3.2 \\
Total & 314 & 100 \\
\hline
\end{tabular}

The best thing connected with any research is the association of young individuals with the research. It is found from the analysis that $42 \%$ of the respondents were relating to the age bracket of 25-30 years, which is indeed an effective sign because it shows the transparency of the research. It is followed by the age bracket of 20-25 years that proportionate to $29.6 \%$ of the total respondents. Current Level of Job and Area of Working are some other questions that have been asked with the respondents. The answers are mentioned in the below-mentioned charts

\section{Current level of Job}

\begin{tabular}{lll}
\hline & Frequency & Percent \\
\hline Entry & 95 & 30.3 \\
Middle & 171 & 54.5
\end{tabular}




\begin{tabular}{lll} 
Top & 48 & 15.3 \\
Total & 314 & 100 \\
\hline
\end{tabular}

\section{Area of working}

\begin{tabular}{lll}
\hline & Frequency & Percent \\
\hline Others & 48 & 15.3 \\
HR & 20 & 6.4 \\
Supply Chain & 22 & 7 \\
Marketing & 31 & 9.9 \\
Operations & 32 & 10.2 \\
Finance & 40 & 12.7 \\
Banking & 36 & 11.5 \\
Education & 85 & 27.1 \\
Total & 314 & 100 \\
\hline
\end{tabular}

Nearly $54 \%$ of the total respondents were associated with the Middle level. It means that they at the level of supervisor or assistant managers. However, $15.3 \%$ of the respondents were associated with a top management position. The area of working is essential to persuade the researcher for data collection transparency. It is found from the analysis that $27.1 \%$ of the total respondents were relating to the Education field followed by the field of Finance and Banking with the proportion of $12.7 \%$ and $11.5 \%$ respectively. Working hours have also been found from the analysis, and the output is as follows

\section{Normal Working Hours}

\begin{tabular}{lll}
\hline & Frequency & Percent \\
\hline Discretionary/urregulated & 59 & 18.8 \\
Discretionary/urregulated & 28 & 8.9 \\
Timetable work (i.e. following a duty rota) & 19 & 6.1 \\
Shift work, three-shift & 20 & 6.4 \\
Shift work, two-shift & 22 & 7 \\
Night Work (about 06:00 pm06:00 am) & 18 & 5.7 \\
Evening Work (about 06:00 pm-10:00 am) & 19 & 6.1 \\
Day Work (about 06:00 am06:00 pm) & 129 & 41.1 \\
Total & 314 & 100 \\
\hline
\end{tabular}

Nearly $42 \%$ of the respondents which were the highest revealed that the normal working hours for them were at the Day Shift for example 6:00 AM to 6:00 PM. Since, this study is focusing mainly on working women, therefore, it is essential to ask from them about the behavior of their immediate supervisors and fellow workers. The output is as follows; 


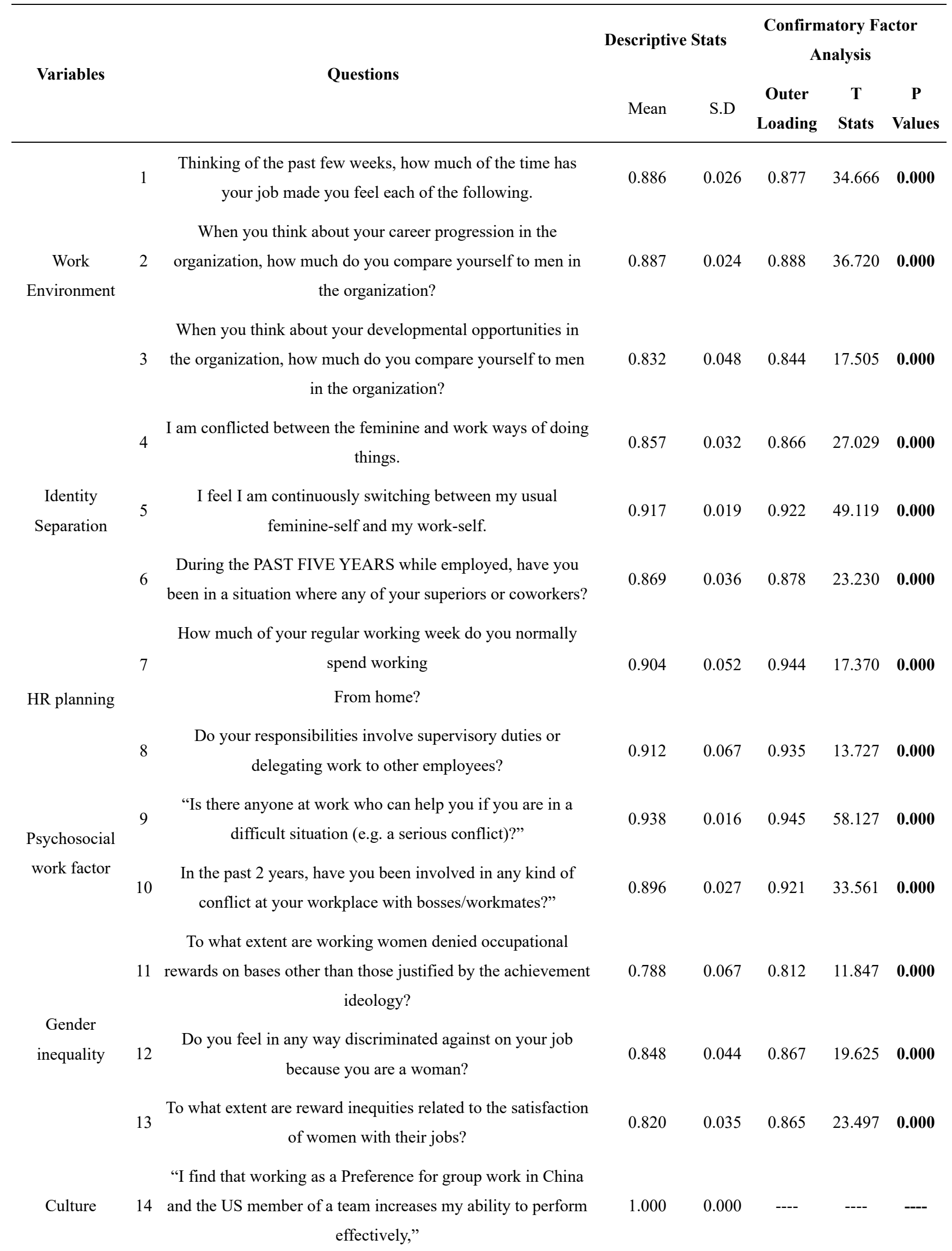




\begin{tabular}{|c|c|c|c|c|c|c|c|}
\hline Women & 15 & $\begin{array}{l}\text { Is Advancement Opportunity have a direct effect on employee } \\
\text { decision on leaving at the Job? }\end{array}$ & 0.953 & 0.014 & 0.982 & 67.706 & 0.000 \\
\hline $\begin{array}{l}\text { Workforce } \\
\text { turnover }\end{array}$ & 16 & $\begin{array}{l}\text { Does a hostile environment for both the genders have a great } \\
\qquad \text { effect on } \\
\text { Turnover? }\end{array}$ & 0.950 & 0.016 & 0.991 & 58.641 & 0.000 \\
\hline \multirow[t]{2}{*}{ Diversity } & 17 & $\begin{array}{l}\text { Leadership development opportunities are designed to } \\
\text { increase diversity in higher-level positions within the } \\
\text { organization (e.g., mentoring, coaching, etc.). }\end{array}$ & 0.889 & 0.036 & 0.911 & 24.761 & 0.000 \\
\hline & 18 & $\begin{array}{l}\text { Organization's employee attitude/satisfaction/engagement } \\
\text { survey includes items that relate to organizational diversity. }\end{array}$ & 0.877 & 0.036 & 0.899 & 24.753 & 0.000 \\
\hline \multirow{2}{*}{ Incivility } & 19 & $\begin{array}{l}\text { During the PAST FIVE YEARS while employed, have you } \\
\text { been in a situation where any of your superiors or coworkers: } \\
\text { Paid little attention to your statement or showed little interest } \\
\text { in your opinion? }\end{array}$ & 0.915 & 0.029 & 0.942 & 31.922 & 0.000 \\
\hline & 20 & $\begin{array}{l}\text { During the PAST FIVE YEARS while employed, have you } \\
\text { been in a situation where any of Doubted your judgment on a } \\
\text { matter over which you have responsibility? your superiors or } \\
\text { coworkers? }\end{array}$ & 0.919 & 0.022 & 0.953 & 42.379 & 0.000 \\
\hline \multirow{2}{*}{$\begin{array}{l}\text { Workplace } \\
\text { Conflict }\end{array}$} & 21 & $\begin{array}{c}\text { During the last two years, when you have felt steamrollered or } \\
\text { unfairly treated by your manager/managers, how have you } \\
\text { reacted? }\end{array}$ & 0.898 & 0.065 & 0.921 & 13.920 & 0.000 \\
\hline & 22 & $\begin{array}{l}\text { Are you subject to personal persecution in the form of unkind } \\
\text { words or behavior? from your superiors or fellow workers }\end{array}$ & 0.926 & 0.050 & 0.930 & 18.576 & 0.000 \\
\hline
\end{tabular}

Several results might be drawn from the descriptive statistics. There were several questions asked in the questionnaire regarding different variables to determine the average trend of a particular variable and its subsequent impact on the women's workplace turnover. The first variable/ factor analyzed in the questionnaire was "Work Environment" for which the impact on the women workplace turnover was studied by recording the answers of three questions. The mean value calculated for the response created by respondents of the questionnaire is recorded to be is $0.886,0.887$, and 0.832 respectively. These values show that most of the respondents agree upon the fact that the work environment has a significant impact on women's workplace turnover. Identity separation is yet another important variable that was analyzed through the questionnaire by asking three questions from the respondents. The mean values calculated for these questions are $0.857,0.917$ and 0.869 respectively. These values show that the respondents at the majority agree upon the fact that Identity separation is a phenomenon that takes place at the workplace and significantly affects the women workforce. The third factor/variable that was determined through the questionnaire was Human Resource Planning (HR planning). Based on the results of descriptive statistics, it was found that the mean values for the recorded in response to the two questions asked regarding Human Resource Planning (HR planning) were 0.904 and 0.914 respectively. This value shows the 


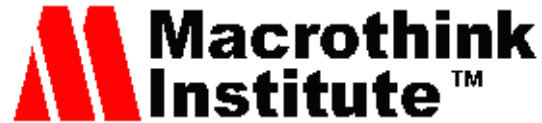

trend of significant effect that the HR policy of an organization imparts on the women workplace turnover. When it comes to the Psychosocial Work Factor, there were two questions asked in the questionnaire to study the relationship of this factor with the women workplace incivility and turnover. The mean values for the responses created by the respondents for these two questions were recorded as 0.938 and 0.896 respectively. This value shows that there is a great impact of several psychological factors that govern the attitude of employees towards the female workers and other such psychosocial factors that might influence women at work. Another key factor that was estimated by the questionnaire is Gender Inequality. It was recorded by getting the response from two questions in the questionnaire circulated in the respondents. It was found that the mean values for both of the questions recorded were 0.848 and 0.840 respectively. Such a ratio depicts that there is a great impact of gender inequality on workplace conflicts related to women and the subsequent Women Workplace Turnover as the women at the workplace primarily face this issue that morally degraded them to work. When it comes to relating the impact of Culture to the workplace conflicts related to women at work. It has been found that the mean value is 1.000 which shows that culture plays no role in the determination of women workplace conflicts and the subsequent women workplace turnover. Another key variable that was determined by the responses created in the questionnaire was Women Workplace Turnover. It was asked in two questions. The mean values for which were estimated as 0.953 and 0.950 respectively. The women workplace turnover is found to be an important factor that is prevalent in the organizations where the female workforce is present in the majority. The next factor that was determined was Diversity at work. Two questions in the questionnaire were asked to determine its impact on the women workplace turnover. It was found that the mean values for the responses created by the respondents for these questions were 0.899 and 0.877 respectively. This ratio shows that Diversity plays a key role in determining the Women's Workplace turnover as indicated by the respondents. Another important factor that was identified to be an important variable in determining the women workplace turnover was workplace Incivility. The mean values for the two questions asked about this variable by the respondents were 0.915 and 0.919 respectively. These values show that there is somehow a relationship between workplace incivility and the women workplace turnover as incivility plays a distinctive role in the development of several workplace conflicts one of them might be women workplace turnover. The last variable that was determined was the Workplace conflict through two questions in the questionnaire. The mean values for the responses created by the respondents against these questions were recorded through descriptive analysis as 0.898 and 0.926 respectively. These values show that the majority of respondents agree upon the fact that workplace conflict is an important variable in determining the reasons behind women's workplace conflicts and turnover.

\subsection{Structural Equation Modeling}

To test the study hypothesis we have used the structural equation model (SEM) whereas the testing has been gone through Smart PLS software. Moreover, to evaluate the indirect and direct effects of all the constructs the testing was done. The use of (SEM) structural equation model has been observed to be a foremost procedure that has been used below different regression models and methods (Barron \& Kenny, 1986). It used to evaluate the structural 
relationship between exogenous and endogenous variables. It includes factor analysis and multivariate analysis. Moreover, the equation of regression targets at explaining each construct to assess the cause and effect relationship while all of the factors in the causal model could demonstrate their cause and effect at the exact time. Likewise, the idea of using this model ensures to apply the technique of bootstrapping which has been viewed as reasonable for both small and large sample sizes and does not require any kind of indirect effect (Hayes, 2013). To check all direct and indirect effects, a technique has been implemented which is known as bootstrapping (Shrout \& Bolger, 2002).

\subsubsection{Measurement of Outer Model}

The goal of the measure of fit in the measurement model is to study the reliability and validity of the instrument and to check its reliability and validity we perform the test of convergent validity and discriminate validity in software naming Smart PLS.

\subsubsection{Composite Reliability}

Reliability implies the stability of questionnaire outcomes. For a similar target population, at whatever point the questioner reutilizes the questionnaire it will give a similar outcome. It demonstrates inside consistency \& repeatability of the survey are high. The primary measure for unwavering quality is to maintain a strategic distance from unfairness in research. In this manner, it tends to be improved by testing the pursuit procedure and investigation, as is done utilizing diverse research and examination techniques or different researchers. This also incorporates the dependability and legitimacy of the exploration.

The reliability of the measurement instruments was evaluated using composite reliability. All the values were above the normally used threshold value i.e. 0.70. This is the accepted reliability value range. Estimation of reliability can be done by the degree of constancy that lies amongst various variables (Yaghi, 2016).

\subsubsection{Factor Loadings Significant}

A table of descriptive statistics also mentioned loadings used in (CFA) confirmatory factor analysis. Construct with the loading of .5 are consider as strong loading variables whereas the constructs with the loading of below .5 are considered as less is better to be removed from the table.

\subsubsection{Convergent Validity}

Convergent validity is the level of agreement in at least two measures of a similar construct (Yaghi, 2016). Convergent validilty was assessed by inspection of variance mined for each factor. Conferring to Fernandez and Lee (2016), if the, variance extracted value is greater than 0.5 then convergent validity is established and the result is drawn that the loadings are good but less than 0.5 are termed as less effective for the study.

The following table displays the result.

\begin{tabular}{llll}
\hline Variables & Cronbach's Alpha & Composite Reliability & Average Variance Extracted (AVE) \\
\hline Culture & 1.000 & 1.000 & 1.000 \\
Diversity & 0.726 & 0.726 & 0.570 \\
\hline
\end{tabular}




\begin{tabular}{llll}
\hline Gender Inequality & 0.767 & 0.759 & 0.518 \\
HR Planning & 0.804 & 0.807 & 0.678 \\
Identity Separation & 0.858 & 0.860 & 0.671 \\
Incivility & 0.815 & 0.815 & 0.689 \\
Psychosocial Work Factor & 0.816 & 0.829 & 0.711 \\
Women Workforce Turnover & 0.899 & 0.899 & 0.817 \\
Work Environment & 0.841 & 0.842 & 0.641 \\
Work Conflict & 0.815 & 0.817 & 0.691 \\
\hline
\end{tabular}

\subsubsection{Discriminant Validity}

Discriminate validity can be defined as any single construct when it differs from other constructs in the model (Chen, Wang, \& Tang, 2016). Discriminate validity results are satisfactory when the constructs are having an AVE loading more than 0.5 which means that a minimum of $50 \%$ of the variance was taken by the construct (Chen, Wang, \& Tang, 2016). Discriminate validity is established if the elements which are in diagonal are significantly higher than those values in off-diagonal in the parallel rows and columns. Discriminant Validity tests are being conducted to see whether non-related ideas or measurements are in fact unrelated or not. An effective assessment of discriminant legitimacy demonstrates that a trial of an idea isn't exceptionally associated with different tests intended to quantify hypothetically various ideas. The table for Discriminant Validity is given below:

\begin{tabular}{|c|c|c|c|c|c|c|c|c|c|c|}
\hline & 1 & 2 & 3 & 4 & 5 & 6 & 7 & 8 & 9 & 10 \\
\hline Culture & 1.000 & & & & & & & & & \\
\hline Diversity & 0.319 & 0.886 & & & & & & & & \\
\hline Gender Inequality & 0.419 & 0.435 & 0.823 & & & & & & & \\
\hline HR Planning & 0.163 & 0.469 & 0.340 & 0.914 & & & & & & \\
\hline Identity Separation & 0.358 & 0.650 & 0.573 & 0.528 & 0.883 & & & & & \\
\hline Incivility & 0.258 & 0.634 & 0.390 & 0.439 & 0.524 & 0.919 & & & & \\
\hline Psycho-social work Factor & 0.421 & 0.396 & 0.663 & 0.255 & 0.518 & 0.354 & 0.918 & & & \\
\hline Women Workforce Turnover & 0.556 & 0.372 & 0.584 & 0.215 & 0.415 & 0.301 & 0.416 & 0.953 & & \\
\hline Work Environment & 0.413 & 0.560 & 0.631 & 0.320 & 0.707 & 0.409 & 0.459 & 0.613 & 0.871 & \\
\hline Workforce Conflict & 0.332 & 0.202 & 0.266 & 0.073 & 0.183 & 0.372 & 0.158 & 0.423 & 0.258 & 0.918 \\
\hline
\end{tabular}

\subsection{Model Fit Measures}

The fitness of the model in SEM-PLS is defined by various measures such as standardized root-mean-square residual (SRMR), and the exact model fits like d_ULS and d_G, Normed Fit Index (NFI), and $\chi 2$ (Chi-square). The model fit measures consisting of the measured 


\section{Macrothink}

Human Resource Research

ISSN 1948-5441

2020, Vol. 4, No. 1

value of both the saturated model, as well as the estimated model, are reported in the above Table. The saturated model assesses the correlation between all constructs. The estimated model, on the other hand, takes model structure into account and is based on the total effect scheme.

\section{Fit Summary}

\begin{tabular}{llc} 
& Saturated Model & Estimated Model \\
\hline SRMR & 0.360 & 0.095 \\
d_ULS & 0.266 & 0.130 \\
d_G & 0.115 & 0.152 \\
Chi-Square & 0.186 & 0.117 \\
NFI & 0.200 & 0.179 \\
\hline
\end{tabular}

\subsection{Hypothesis Testing}

In PLS-SEM, bootstrapping is one of the key strides, which gives the data of constancy of factor guesstimate. Sub-tests are drawn everywhere from the first example including substitution, in this process (Tongchaiprasit \& Ariyabuddhiphongs, 2016). Bootstrapping provides information on the stability of the coefficient estimate. In this process, a large number of sub-samples are drawn from the original sample with replacement (Ali, Metz, \& Kulik 2015). After running the bootstrap routine, SmartPLS shows the t-values for structural model estimates derived from the bootstrapping procedure. The results of path coefficients for all the hypotheses are shown in the following table. The t-value greater than $1.96(\mathrm{p}$ $<.005)$ shows that the relationship is significant at 95\% confidence level $(\alpha=0.05)$. Paths showing whether the relationship between measured and latent variables are significant or not. The path diagram showed in Figure 1. 


\section{I Macrothink}

Human Resource Research

ISSN 1948-5441

2020, Vol. 4, No. 1

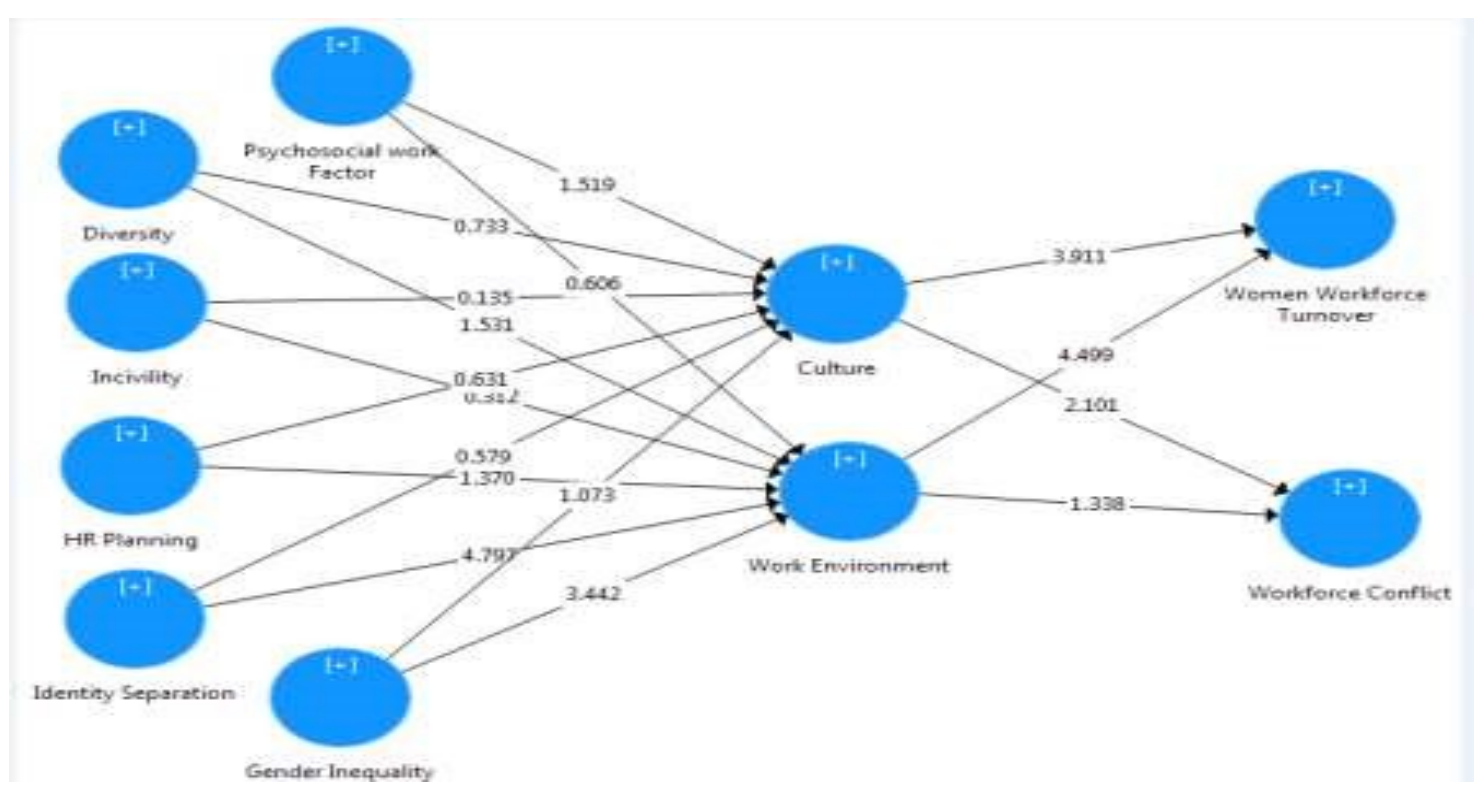

Figure 1. Research Model

\subsection{Testing of Hypothesis}

There are a total of 16 hypotheses that have been selected for the same assessment. Each of the hypotheses has been evaluated differently. The hypothesis output is as follows;

\begin{tabular}{|c|c|c|c|c|c|}
\hline & $\begin{array}{l}\text { Original } \\
\text { Sample } \\
\text { (O) }\end{array}$ & $\begin{array}{l}\text { Sample } \\
\text { Mean (M) }\end{array}$ & $\begin{array}{l}\text { Standard } \\
\text { Deviation } \\
\text { (STDEV) }\end{array}$ & $\begin{array}{l}\text { T Statistics } \\
(|\mathrm{O} / \mathrm{STDEV}| \\
)\end{array}$ & $\begin{array}{l}\mathrm{P} \\
\text { Values }\end{array}$ \\
\hline Culture ->WomenWorkforce Turnover & 0.365 & 0.360 & 0.095 & 3.841 & 0.000 \\
\hline Culture $->$ Workforce Conflict & 0.271 & 0.266 & 0.130 & 2.087 & 0.037 \\
\hline Diversity $->$ Culture & 0.111 & 0.115 & 0.152 & 0.735 & 0.462 \\
\hline Diversity -> Work Environment & 0.183 & 0.186 & 0.117 & 2.573 & 0.016 \\
\hline Gender Inequality $->$ Culture & -0.193 & 0.200 & 0.179 & 1.078 & 0.281 \\
\hline Gender Inequality ->Work Environment & -0.371 & 0.375 & 0.104 & 3.556 & 0.000 \\
\hline HR Planning $->$ Culture & -0.065 & -0.064 & 0.103 & 0.626 & 0.531 \\
\hline HR Planning -> Work Environment & -0.121 & -0.112 & 0.091 & 2.326 & 0.019 \\
\hline Identity Separation $->$ Culture & 0.090 & 0.083 & 0.150 & 0.601 & 0.548 \\
\hline Identity Separation ->WorkEnvironment & 0.493 & 0.488 & 0.099 & 4.977 & 0.000 \\
\hline Incivility -> Culture & 0.018 & 0.019 & 0.131 & 0.134 & 0.893 \\
\hline Incivility -> Work Environment & 0.031 & -0.034 & 0.097 & 0.321 & 0.748 \\
\hline Psychosocial work Factor -> Culture & 0.212 & 0.203 & 0.139 & 2.529 & 0.013 \\
\hline
\end{tabular}




\begin{tabular}{lccccc}
\hline Psychosocial work Factor -> Work Environment & 0.073 & -0.082 & 0.116 & 0.629 & 0.529 \\
Work Environment -> Women Workforce Turnover & 0.462 & 0.458 & 0.102 & 0.000 \\
Work Environment -> Workforce Conflict & 0.146 & 0.152 & 0.104 & 2.406
\end{tabular}

The results showed that Diversity, and Identity Separation have a positive whereas Gender Inequality, and Discriminatory HR Planning have a negative significant effect on the Work Environment. Moreover, the work environment in turn positively affects Women Workforce Turnover and Workforce Conflict. Psychosocial work Factors also positively affect work culture, which subsequently affects both and Women Workforce Turnover, and Conflict. Hence work environment, and culture both play an effective mediatory role in-between these factors and Women Workforce Turnover, and Conflict.

\section{Discussions}

Most of the results are well-correlated with the prior knowledge of workplace conflicts while some of them are surprisingly new to literature such as the role of a better environment in the organizations of Pakistan about women turnover at the workplace. The results showed that Diversity seems to have an insignificant effect on culture but a positive and significant effect on the work environment. as stated by Sharma (2016) that diversity management leads to better environment propagation and an improved collectivistic culture; Pearson (2000) suggests that collectivistic culture is promoted and developed by embracing the role of every employee in an organization that further leads to the development of an improved environment.

Similarly, gender equality and HR planning seem to have a significant negative effect on the work environment. However, it remained insignificant in terms of culture. The social cognitive theory recognizes every individual equal, irrespective of gender while identity separation and gender inequality negate this. The negative correlation shows that the prevalence of gender inequality and identity separation among male and female employees of Pakistani organizations leads to the development of women workforce conflicts as suggested by Choi (2018), explaining the Chinese employee's workforce rights. Similarly, discriminatory Human Resource policy of an organization can lead to the development of a disruptive culture and environment of an organization that further leads to the arousal of negative workplace conflicts regarding women workforce and turnover. Williams et al., (2018) have undoubtedly explained that the discriminations created in selecting the workforce depending upon age, gender, race or ethnicity lead to the development of a flawed environment that further affects the women workforce and the subsequent turnover disruption.

Identity Separation seems to affect the work Environment positively, however, it remained insignificant for culture. Incivility has no significant effect on either culture or work environment. As suggested by Stamkou, et al., (2018) that the culture is always negatively correlated with the workplace incivility. Uncivil behavior among employees degrades the integrity of workplace culture and leads to further disruptions (Pearson, 2000).

Psychosocial work Factor seems to have a positive effect on Culture, however, it remained 
insignificant for the work environment. As contended by (Williams et al., 2018), Psychosocial workplace Factors have been responsible for bringing about positive correlation in the women workplace conflicts.

And lastly, collectivist Culture, as well as work environment both, have a positive and significant effect on both reducing Women Workforce Turnover as well as Workforce Conflict. Findings imply that Culture and work environment should have been considered in a professional and well-directed manner. A collectivism-oriented culture promotes the inclusion of every individual at the workplace as claimed by Pearson (2000), the organizations that maintain inclusiveness have more chances to maintain a better environment that further leads to lower conflicts related to women's workforce.

\section{Conclusion}

Female workplace conflicts and turnover are one of the most important factors associated with the organizations and companies in Pakistan. It is important to address these issues in light of several moderators, dependent and independent variables. The growing trend of this issue at an exponential rate demands it to be discussed by the researchers to find the possible antecedents of this issue, relating factors, governing factors, responsible factors and the possible domains of culture and norms involved in making possible assumptions or framework to explain the main cause of this prevalent and propagating issue of the organizations of Pakistan. This issue was very limitedly discussed in the literature. There was no piece of literature or research done in Pakistan specifically. For this purpose, this study was designed to find out the relationship between various cultural \& social, environmental factors and the workplace conflicts that the organization has. It is important to address these problems to get them resolved. This research was designed to fill this gap for the literature related to women workforce conflicts and women turnover in the organizations of Pakistan. This research is expected to add a valuable addition to the existing knowledge of antecedents of the women workforce conflicts and turnover. It was done by distributing a questionnaire designed carefully based upon the prior knowledge obtained from the literature. It was found that the possible factors that need to be considered as independent variables for this research such as gender inequalities, workplace incivility, identity separation, discriminatory human resource policies and other such issues.

The findings from this research that there are several different antecedents of Women workplace turnover and conflicts such as derived by varying cultural and environmental conditions of an organization or workplace such gender inequality, work segregation, psychosocial work factors, human resource planning and other such factors. It was found that gender inequality, identity separation, discriminatory human resource policies of an organization and other such factors promote the prevalence of conflicts related to women turnover and workforce in various organizations of Pakistan.

This research might be used in future perspectives of research related to the organizations of Pakistan. It might be used to find the possible solutions to such issues that have been prevalent for decades in Pakistan to gain an improved status of the organizations of Pakistan.

\section{References}

Angelov, N., Johansson, P., \& Lindahl, E. (2016). Parenthood and the gender gap in pay. 
Journal of Labor Economics, 34(3), 545-579. https://doi.org/10.1086/684851

Angelov, N., Johansson, P., \& Lindahl, E. (2013). Is the Persistent Gender Gap in Income and Wages Due to Unequal Family Responsibilities? Working Paper IFAU, (7181).

Ajaz, S., Mehmood, B., \& Kashif, M. (2015). Impact of work-family conflict on female intent to quit: Descriptive study of commercial banks of Faisalabad, Pakistan. International Journal of Academic Research in Accounting, Finance and Management Sciences, 5(4), 74-83. https://doi.org/10.6007/IJARAFMS/v5-i4/1847

Ali, M., Metz, I., \&Kulik, C. T. (2015). Retaining a diverse workforce: the impact of gender-focused human resource management. Human Resource Management Journal, 25(4), 580-599. https://doi.org/10.1111/1748-8583.12079

Anker, R. (1997). Theories of occupational segregation by sex: An overview. International Labour Review, 136(3), 315-339.

Anker, M., \& Arima, Y. (2011). Male-female differences in the number of reported incident dengue fever cases in six Asian countries. Western Pacific Surveillance and Response, 2(2), e1-e1. https://doi.org/10.5365/wpsar.2011.2.1.002

Arnsten, A. F. T., Raskind, M. A., Taylor, F. B., Connor, D. F., Arpana, R., Bilgel, N., ... Obedgiu, V. (2018). Dealing with or Reporting "Unacceptable" behavior (with additional thoughts about the "bystander effect"). Journal of the International Ombusman Association, 2(3), 1-18. https://doi.org/10.1080/09585192.2016.1164216

Avgar, A. (2017). Integrating Conflict: A Proposed Framework for the Interdisciplinary Study of Workplace Conflict and its Management. ILR Review, 0019793919885819.

Ayoko, O. B. (2016). Workplace conflict and willingness to cooperate: The importance of apology and forgiveness. International Journal of Conflict Management, 27(2), 172-198. https://doi.org/10.1108/IJCMA-12-2014-0092

Altonji, J. G., \& Blank, R. M. (1999). Chapter 48 Race and gender in the labor market. Handbook of Labor Economics. https://doi.org/10.1016/S1573-4463(99)30039-0

Baillien, E., Camps, J., Van den Broeck, A., Stouten, J., Godderis, L., Sercu, M., \& De Witte, H. (2016). An eye for an eye will make the whole world blind: Conflict escalation into workplace bullying and the role of distributive conflict behavior. Journal of Business Ethics, 137(2), 415-429. https://doi.org/10.1007/s10551-015-2563-y

Burgess, D., \& Borgida, E. (1999). Who women are, who women should be: Descriptive and Prescriptive Gender Stereotyping in Sex Discrimination. Psychology, Public Policy, and Law, 5(3), 665-692. https://doi.org/10.1037/1076-8971.5.3.665

Browne, K. R. (2006, March). Sex, power, and dominance: The evolutionary psychology of sexual harassment. Managerial and Decision Economics. https://doi.org/10.1002/mde.1289

Browne, K. R. (2006). Evolved sex differences and occupational segregation. Journal of Organizational Behavior, 27(2), 143-162. https://doi.org/10.1002/job.349 


\section{$\triangle$ Macrothink}

Cialdini, R. B., \& Trost, M. R. (1998). Social Influence: Social Norms, Conformity, and Compliance. In G. Lindzey, D. Gilbert, \& S. T. Fiske (Eds.), The Handbook of Social Psychology (Volume 2, pp. 151-192). Oxford University Press. Retrieved from http://books.google.com/books?hl=en\&lr=\&id=w27pSuHLnLYC\&pgis=1

Cortina, L. M., Magley, V. J., Williams, J. H., \& Langhout, R. D. (2001). Incivility in the workplace: incidence and impact. J. Occup. Health Psychol. 6, 64-80. https://doi.org/10.1037/1076-8998.6.1.64

Chen, J., Wang, L., \& Tang, N. (2016). Half the Sky: The moderating role of cultural collectivism in job turnover among Chinese female workers. Journal of business ethics, 133(3), 487-498. https://doi.org/10.1007/s10551-014-2395-1

Chen, W., Zhang, Y., Sanders, K., \& Xu, S. (2018). Family-friendly work practices and their outcomes in China: the mediating role of work-to-family enrichment and the moderating role of gender. The International Journal of Human Resource Management, 29(7), 1307-1329. https://doi.org/10.1080/09585192.2016.1195424

Chang, J., Connell, J., Burgess, J., \& Travaglione, A. (2014). Gender wage gaps in Australian workplaces: Are policy responses working? Equality, Diversity and Inclusion, 33(8), 764-775. https://doi.org/10.1108/EDI-10-2013-0080

Choi, S. (2018). Managing flexible work arrangements in government: Testing the effects of institutional and managerial support. Public Personnel Management, 47(1), 26-50. https://doi.org/10.1177/0091026017738540

Currie, D., \& Teague, P. (2016). Economic Citizenship and Workplace Conflict in Anglo-American Industrial Relations Systems. British Journal of Industrial Relations, 54(2), 358-384. https://doi.org/10.1111/bjir.12150

Currie, D., Gormley, T., Roche, B., \& Teague, P. (2017). The management of workplace conflict: Contrasting pathways in the HRM literature. International Journal of Management Reviews, 19(4), 492-509. https://doi.org/10.1111/ijmr.12107

Danielsson, C. B., Bodin, L., Wulff, C., \& Theorell, T. (2015). The relation between office type and workplace conflict: A gender and noise perspective. Journal of Environmental Psychology, 42, 161-171. https://doi.org/10.1016/j.jenvp.2015.04.004

Einarsen, S., Skogstad, A., Rørvik, E., Lande, Å. B., \& Nielsen, M. B. (2018). Climate for conflict management, exposure to workplace bullying and work engagement: a moderated mediation analysis. The International Journal of Human Resource Management, 29(3), 549-570. https://doi.org/10.1080/09585192.2016.1164216

Equality, G. (2009). She Figures 2009. Economy and Society (pp. 1=124). https://doi.org/10.2777/10329

Gender equality. (2017). Nursing Management (Harrow, London, England : 1994), 23(9), 12. https://doi.org/10.7748/nm.23.9.12.s14 
Gifford, J., Gould, M., Latreille, P., \& Urwin, P. (2016). Workplace Conflict: Who, Where, When, and Why? In Reframing Resolution (pp. 57-77). Palgrave Macmillan, London. https://doi.org/10.1057/978-1-137-51560-5_4

Griffeth, R. W., Hom, P. W., \& Gaertner, S. (2000). A meta-analysis of antecedents and correlates of employee turnover: Update, moderator tests, and research implications for the next millennium. Journal of Management, 26(3), 463-488. https://doi.org/10.1177/014920630002600305

Grimshaw, D., \& Rubery, J. (2015). The motherhood pay gap: A review of the issues, theory and international evidence. International Labour Office - Conditions of Work and Employment Series (Vol. 57, pp. 1-69). https://doi.org/10.1017/CBO9781107415324.004

Greenhaus, J. H., \& Beutell, N. J. (1985). Sources of Conflict Between Work and Family Roles. Academy of Management Review, 10(1), 76-88. https://doi.org/10.5465/amr.1985.4277352

Hippel, C. V., Sekaquaptewa, D., \& Mcfarlane, M. (2015). Stereotype Threat Among Women in Finance. Psychology of Women Quarterly, 39(3), 405-414. https://doi.org/10.1177/036 1684315574501

Hurst, J., Leberman, S., \& Edwards, M. (2016). Women managing women. Gender in Management: An International Journal, 31(1), 61-74. https://oi.org/10.1108/GM-03-20 15-0018

Jabeen, F., Friesen, H. L., \& Ghoudi, K. (2018). Quality of work life of Emirati women and its influence on job satisfaction and turnover intention: Evidence from the UAE. Journal of Organizational Change Management, 31(2), 352-370. https://doi.org/10.1108/JOCM-012017-0016

Jnaneswar, K. (2016). Relationship between work-life balance, turnover intention, and organizational support for work-life balance: A study in the IT Industry in Kerala. Prabandhan: Indian Journal of Management, 9(5), 33-44. https://doi.org/10.17010/ pijom/2016/v9i5/92569

JL, L. F. Q. R. S. (1971). Sex discrimination against the American working women. American Behavioral Scientist, 15, 238-254. https://doi.org/10.1177/000276427101500207

Kabeer, N. (2005). Gender equality and women's empowerment: A critical analysis of the third Millennium Development Goal. Gender and Development, 13(1), 13-24. https://doi.org/10.1080/13552070512331332273

Liu, Z., Deng, C. J., Wu, B., \& Ge, L. (2017). Workplace Conflict, Status-conferral Criteria and Job Performance: Status Competition Perspective. In Academy of Management Proceedings (Vol. 2017, No. 1, p. 16085). Briarcliff Manor, NY 10510: Academy of Management. https://doi.org/10.5465/AMBPP.2017.16085abstract

Livanos, I., Yalkin, Ç., \& Nuñez, I. (2009). Gender employment discrimination: Greece and the United Kingdom. International Journal of Manpower, 30(8), 815-834. 
https://doi.org/10.1108/01437720911004443

Levitin, T., Quinn, R. P., \& Staines, G. L. (1971). Sex Disertmznataon Against the American Working Woman. American Behavioral Scientist, 15(2), 237-254. https://doi.org/10.1177/ 000276427101500207

Mayende, T. S., \& Musenze, I. A. (2018). Ethical leadership and staff retention: The moderating role of job resources in Uganda's healthcare sector. SA Journal of Industrial Psychology, 44(1), 1-10. https://doi.org/10.4102/sajip.v44i0.1531

Mears, A., \& Connell, C. (2016). The paradoxical value of deviant cases: Toward a gendered theory of display work. Signs, 41(2), 333-359. https://doi.org/10.1086/682922

Mobley, W. H. (1977). Intermediate linkages in the relationship between job satisfaction and employee turnover. Journal of Applied Psychology, 62(2), 237-240. https://doi.org/10.1037/0021-9010.62.2.237

Nadler, J. T., \& Stockdale, M. S. (2012). Workplace gender bias: Not just between strangers. North American Journal of Psychology, 14(2), 281-292.

Nyberg, A., Leineweber, C., \& Hanson, L. M. (2015). Gender differences in psychosocial work factors, work-personal life interface, and well-being among Swedish managers and non-managers. International archives of occupational and environmental health, 88(8), 1149-1164. https://doi.org/10.1007/s00420-015-1043-0

ÖZBILGIN, M. F. (2007). Gender and Jobs: Sex Segregation of Occupations in the World? By Richard Anker. Gender, Work \& Organization, 14(5), 502-504. https://doi.org/10.1111/j.1468-0432.2007.00362_2.x

Pitafi, A. H., Liu, H., \&Cai, Z. (2018). Investigating the relationship between workplace conflict and employee agility: The role of enterprise social media. Telematics and Informatics, 35(8), 2157-2172. https://doi.org/10.1016/j.tele.2018.08.001

Pearson, C. M., Andersson, L. M., \& Porath, C. L. (2000). Assessing and attacking workplace incivility. Organizational Dynamics, 29(2), 123-137.

Rubery, J., \& Grimshaw, D. (2015). The 40-year pursuit of equal pay: A case of constantly moving goalposts. Cambridge Journal of Economics, 39(2), 319-343. https://doi.org/10. 1093/cje/beu053

Santhanam, N., Kamalanabhan, T. J., Dyaram, L., \& Ziegler, H. (2015). Examining the moderating effects of organizational identification between human resource practices and employee turnover intentions in Indian hospitality industry. GSTF Journal on Business Review (GBR), 4(1). https://doi.org/10.5176/2251-1970_THoR14.05

Stamkou, E., van Kleef, G. A., Homan, A. C., \& Galinsky, A. D. (2016). How norm violations shape social hierarchies: Those who stand on top block norm violators from rising up. Group Processes and Intergroup Relations, 19(5), 608-629. https://doi.org/10.1177/13 68430216641305 


\section{Macrothink}

Human Resource Research

ISSN 1948-5441

2020, Vol. 4, No. 1

Sharma, A. (2016). Managing diversity and equality in the workplace. Cogent Business and Management, 3(1). https://doi.org/10.1080/23311975.2016.1212682

Tongchaiprasit, P., \&Ariyabuddhiphongs, V. (2016). Creativity and turnover intention among hotel chefs: The mediating effects of job satisfaction and job stress. International Journal of Hospitality Management, 55, 33-40. https://doi.org/10.1016/j.ijhm.2016.02.009

Upchurch, M., \&Grassman, R. (2016). Striking with social media: The contested (online) terrain of workplace conflict. Organization, 23(5), 639-656. https://doi.org/10.1177/ 1350508415598248

Wang, I. A., Lee, B. W., \& Wu, S. T. (2017). The relationships among work-family conflict, turnover intention and organizational citizenship behavior in the hospitality industry of Taiwan. International Journal of Manpower, 38(8), 1130-1142. https://doi.org/10.1108/IJM $-04-2015-0056$

Williamson, A., \& Friswell, R. (2013). Fatigue in the workplace: causes and countermeasures. Fatigue: Biomedicine, Health \& Behavior, 1(1-2), 81-98. https://doi.org/10.1080/ 21641846.2012.744581

Williamson, G. (2007, August). Providing leadership in a culturally diverse workplace. AAOHN Journal: Official Journal of the American Association of Occupational Health Nurses. https://doi.org/10.1177/216507990705500805

Warr, P. (1990). The measurement of well-being and other aspects of mental health. Journal of Occupational Psychology, 63(3), 193-210. doi: 10.1111/j.2044-8325.1990.tb00521.x

Workplace Gender Equality Agency. (2018). Gender workplace statistics at a glance. Retrieved from https://www.wgea.gov.au/sites/default/files/Stats_at_a_Glance.pdf

Yaghi, A. (2016). Is it the human resource policy to blame? Examining intention to quit among women managers in Arab Middle Eastern context. Gender in Management: An International Journal, 31(7), 479-495. https://doi.org/10.1108/GM-11-2015-0094

Yu, H. H. (2019). Work-life balance: an exploratory analysis of family-friendly policies for reducing turnover intentions among women in US federal law enforcement. International Journal of Public Administration, 42(4), 345-357. https://doi.org/10.1080/0190 0692.2018.1463541

Zurbrügg, L., \& Miner, K. N. (2016). Gender, Sexual Orientation, and Workplace Incivility: Who Is Most Targeted and Who Is Most Harmed? Frontiers in Psychology, 7. https://doi.org/10.3389/fpsyg.2016.00565

\section{Copyright Disclaimer}

Copyright for this article is retained by the author(s), with first publication rights granted to the journal.

This is an open-access article distributed under the terms and conditions of the Creative Commons Attribution license (http://creativecommons.org/licenses/by/3.0/). 